on November 8, 1934, published in the March issue of the Institute's Journal, constituted an extremely valuable review of the more immediate past and future of metallurgical development. Under the title of "Recent Trends and Future Developments in Metallurgical Research", Dr. Moore surveyed the application of physical and physico-chemical methods to the study of metals and alloys, with particular reference to the industrial application of the results of research. In the period under review-the past decade-the output of metallurgical research has undoubtedly been unparalleled; but in Dr. Moore's view the main bulk of this large output has been concerned with the exploitation of fundamental concepts which had been developed more than ten years ago. Research in progress at the present time is reviewed under six main heads: melting and solidification, working of metals, heat treatment, mechanical properties, corrosion, and electro-deposition, and the directions in which work may be expected to proceed in the near future are outlined. The impression gained from this exceptionally interesting and virile address is one of boundless fields of research, offering fascinating possibilities in the extension of the use of metals for a very wide range of purposes for the benefit of civilisation.

\section{Science and Humanism}

Is the quest for a unity underlying the rich variety of the universe, philosophers are in constant danger of limiting themselves to unreal abstractions and verbal dialectic. Both those who call themselves pragmatists, as dealing with things rather than with words, and those who prefer the fuller name of humanists, find that science, the most objective of human experiences, has a large contribution to make to our general body of thought. As is pointed out by A. Rey in "Les Mathématiques en Grèce" (Actualités Scientifiques, 217. Paris: Hermann et Cie., 1935) the study of the history of science may be recommended on two grounds. It may make scientific thought more accessible to philosophers, and may do something to break down, among scientific workers themselves, that narrow specialisation which is so prevalent to-day. Among the ancient Greeks, as also in the Renaissance, both ages of humanism and free inquiry, science had a considerable place, though not an exclusive one. The humanism of to-day has at its disposal an embarrassing array of tempting dishes; the difficulty is to make a well-balanced selection from them, and to get the whole range of mental vitamins without suffering from hypervitaminosis.

\section{Description and Identification of Species}

IN spite of the three quarters of a million species of animals which have been described binomially, it is remarkable how little there is of organised plan in the descriptions, taken as a whole. Some authors of new species are content with a few lines of characterisation, others seem to describe, not a species, but the total characters of an individual specimen. It is partly that species are not fixed, and that few writers, even on the same group, would agree upon the characters to be selected as criteria of specific rank, partly that the critical characters within different groups appear to be so diverse, that no common plan would fit more than a relatively few. Dr. Séverin Icard has made a bold attempt to standardise descriptions of species by advocating a method which he calls "la méthode des nombres signalétiques" (Revue de Path. comp. Hyg. gen., Nov. 1934). It looks quite simple. Shortly, it is that, in regular order, parts of the specimen to be identified or described are examined, and the result for each part is represented by a number. The key to the parts to be examined for a particular group, and to the number corresponding to a particular character, say, legs yellow, is to be found in a set of "Tables de correspondance". Thus the special character of each part has its own particular number, a short-hand way of writing a description which normally would contain at least a few words for each part.

\section{Species Formula}

IN describing a beetle, for example, Dr. Icard chooses seven characters, always read in the same order-colour of thorax, colour of elytra, form of thorax, form of elytra, form of feet and tarsi, form of antennæ, form of head. Each character, in a particular specimen, is represented by a numberthe nombre signalétique or descriptive number, so that the total description of the specimen as regards specific characters may be represented by a series of numbers-the formule signalétique or specific formula. We wish to identify a beetle; we translate one by one its characters into the appropriate number; then having composed our specific formula we search for this particular formula in another book of words, "Le Répertoire général", and if we find the formula there we shall also find opposite it the name of the species which possesses this characteristic association of characters. It is an attractive idea that the plant and animal worlds should be so completely tabulated that a set of symbols would identify any of their members, and if the method would enforce upon describers of species definiteness in characterisation and brevity, it might be well worth a trial.

\section{Suggested Biological Survey for Union of South Africa}

IN the South African Journal of Science (Nov. 1934, p. 396), Dr. R. Bigalke makes a plea for the inauguration of a biological survey in the Union. During 1911-33 the Provinces spent $\mathfrak{f 6 0 7 , 6 7 4}$ in connexion with fish and game preservation and the destruction of vermin, and the suggestion is that a biological survey would furnish scientific information for the more efficient use of such expenditure. The survey would be a unit of the Department of Agriculture, and it would set in the forefront of its aims the solution of pressing economic problems, such as the biology and control of predatory animals, of noxious rodents, or rabies transmitters, and the relation of wild birds to agriculture. Before such 
investigations had progressed far, the need for faunistic surveys would become obvious, and for the prosecution of these co-operation would be sought with the various museums. The author estimates that such a survey could be set going with a staff of not less than six biologists, who should have taken zoology as a major subject and botany and geology as minors. But can any thorough study of fauna be carried out without recourse to fairly thorough statistical analysis, and the author says nothing about mathematical qualifications.

\section{The Men of the Trees}

THE tenth annual report of the Society of the Men of the Trees reviews the work of the past year, which has shown an increased membership of the Society, inaugurated by Mr. St. Barbe Baker. The work of the year has included lectures, meetings and exhibitions. Of the latter, the chief was the International Picture Exhibition, held at Grosvenor House, Park Lane, London, throughout November. Thirty-seven countries assisted the exhibition by sending tree paintings by some of their foremost living artists, and also treasures from the national collections. Several addresses were delivered at meetings by Ambassadors and Ministers accredited to Great Britain. The opening address was given by Field Marshal Viscount Allenby, who dwelt upon the importance of forestry and tree-planting in Great Britain to make good the wastage of the late War. Lord Allenby, even before the War was over in Palestine, had started to restore the land by treeplanting, a commencement which inspired the Men of the Trees to carry on the work. Before opening the exhibition, Lady Georgiana Mure pointed out that forestry and the care of trees is a world-wide thing and that we can "meet our friends from Overseas on a common ground of good fellowship, occasioned by the mutual admiration and love of the countryside and its chief ornament, trees". Mr. Baker directed attention to the advantage from an æsthetic point of view, as well as the hygienic and economic, of planting up the slagheaps in the Black Country of England, and stated that a part of the proceeds from the exhibition was to be devoted to that object.

\section{Cereal Synonyms}

THe Cereal Synonym Committee has come to a number of decisions on the stocks of cereals which it examined in 1934. In arriving at these decisions, the Committee was guided by the following definition of a cereal synonym : "The Cereal Synonym Committee regard two cereals as synonyms when they present precisely similar morphological characters, and when they also possess identical physiological characters in so far as they can be determined. Even then by this term they do not necessarily imply that these two varieties are of identical origin, though doubtless in the majority of cases they are. The possibility of two cereals of different parentage presenting such a close, if not complete similarity as to mask their individuality has not been lost sight of.
But the Committee have to deal with facts as they are; they, therefore, regard as synonyms all cereals which are identical in the sense used above even when they know that the origins are different. Before the Committee come to a conclusion concerning the synonymity of any variety the breeder and/or the introducer is given an opportunity of demonstrating to the Committee such differences as he may claim to exist between his variety and the type variety." In compliance with the request of the Committee that as much publicity as possible should be given to its decisions, the National Institute of Agricultural Botany, Cambridge, has published a leaflet giving full details of the findings for the wheat, oats and barley varieties investigated.

\section{Review of Agricultural Research}

The Royal Agricultural Society of England has recently issued its Journal for 1934, vol. 95. As last year, "The Farmer's Guide to Agricultural Research" has been incorporated with the annual publication, so that it may be available to every member of the Society. At the same time a number of copies are being bound separately for distribution to the Press and to centres of agricultural education and research. This valuable survey of recent scientific work has. been carried out on the same lines as in previous. years and the authors responsible for the various sections, namely, crops and plant breeding, diseases. of animals, farm implements and machinery, farm economics, dairy farming and dairy work, the feeding of livestock, and soils and fertilisers, are the sameas in 1932. The work dealt with is not limited to research conducted in the British Isles, but includes references to results achieved in any part of the world from which light may be thrown on the problems of British agriculture. A few copies of previous issues (1925-32) are still available.

\section{British Standard Specifications for Laboratory Glassware}

IN further development of the work which is now being carried out by a committee of the Chemical Division of the British Standards Institution in the standardisation of laboratory ware including scientific glassware, British standard specifications have just been issued for graduated measuring cylinders, Crow receivers, Nessler cylinders and Petri dishes. Copies of the specifications (Nos. 604, 605, 612 and 611-1935 respectively) may be obtained from the Publications Department, British Standards Institution, 28, Victoria Street, London, S.W.1, price $2 s .2 d$. each post paid.

\section{New Museum of Practical Geology, South Kensington}

THE opening of the new Museum of Practical Geology, South Kensington, London, S.W.7, and the celebrations of the centenary of the Geological Survey of Great Britain, will take place on July 3-4. The opening ceremony will be performed by H.R.H. the Duke of York on July 3 at 3 p.m. A preliminary account of the proceedings appeared in NATURE of March 23, p. 463. In the final programme now issued, it is announced that the director of the 